\title{
Síndrome de disfunción de órganos y adaptación mitocondrial en el paciente séptico
}

\author{
Alejandro Donoso-Fuentes* y Daniela Arriagada-Santis \\ Unidad de Paciente Crítico Pediátrico, Centro de Responsabilidad del Niño, Hospital Clínico Metropolitano Dra. Eloísa Díaz Insunza, La Florida, \\ Santiago, Chile
}

\begin{abstract}
Resumen
Piedra angular para la sobrevida y la evolución de los organismos es su capacidad de mantener un adecuado balance energético, así como también que las células respondan y se adapten al estrés ambiental. Por ello, ante la presencia de diversos factores se origina una respuesta de protección celular mediante la activación de señalización dependiente de la función mitocondrial. Sin embargo, esta reacción, esencial para la supervivencia individual de las células, puede ser perjudicial para la función orgánica (adaptación inadecuada), transformando el estrecho equilibrio entre ambas en el eje patogénico de la disfunción orgánica y su eventual recuperación en el paciente séptico. Las alteraciones macrocirculatorias y microcirculatorias contribuyen, indudablemente, a la disfunción orgánica en la etapa precoz del choque séptico, mientras que la falla metabólica-bioenergética intrínseca (hipoxia citopática) perpetúa una función celular inadecuada. Por lo tanto, la disfunción mitocondrial es un proceso clave en la inducción del síndrome de disfunción multiorgánica en el paciente séptico. Este síndrome puede considerarse como un complejo fenómeno adaptativo hipometabólico ante un estímulo inflamatorio excesivo y prolongado, para lograr la regulación de la homeostasis energética y la preservación de la función de los órganos. En el futuro, debería producirse una transición entre las opciones terapéuticas actuales consensuadas, que se limitan al control del foco infeccioso y el soporte hemodinámico y vital, hacia una reanimación metabólica basada en las alteraciones moleculares y genéticas desencadenadas por la infección.
\end{abstract}

Palabras clave: Mitocondria. Sepsis. Síndrome de disfunción multiorgánica. Adaptación metabólica. Estrés oxidativo.

\section{Organ dysfunction syndrome and mitochondrial adaptation in the septic patient}

\section{Abstract}

The ability to maintain an adequate energy balance and to respond and adapt to environmental stress at the cellular level are cornerstones for the survival and evolution of organisms. Therefore, in the presence of various factors, a cellular protection response is triggered by activation of mitochondrial function-dependent signaling. However, this essential reaction for individual cell survival can be detrimental to organ function (maladaptation), transforming the close balance between the two into the pathogenetic axis of organ dysfunction and eventual recovery in septic patients. Macrocirculatory and microcirculatory disruption undoubtedly contributes to organ dysfunction in the early stage of septic shock, while intrinsic metabolic-bioenergetic failure (cytopathic hypoxia) perpetuates inadequate cellular function. Therefore, mitochondrial dysfunction is a key process in the induction of multiple organ dysfunction syndrome in the septic patient. This syndrome can be considered as

Correspondencia:

${ }^{*}$ Alejandro Donoso-Fuentes

E-mail: adonosofuentes@gmail.com
Fecha de recepción: 15-10-2020

Fecha de aceptación: 02-02-2021

DOI: 10.24875/BMHIM.20000323
Disponible en internet: 16-12-2021 Bol Med Hosp Infant Mex. 2021;78(6):597-611

www.bmhim.com 1665-1146/C 2021 Hospital Infantil de México Federico Gómez. Publicado por Permanyer. Este es un artículo open access bajo la licencia CC BY-NC-ND (http://creativecommons.org/licenses/by-nc-nd/4.0/). 
a complex hypometabolic adaptive phenomenon in the face of excessive and prolonged inflammatory stimulus to achieve regulation of energy homeostasis and preservation of organ function. In the future, there should be a transition from the current consensus therapeutic options, which are limited to control of the infectious focus, hemodynamic and life support, to metabolic resuscitation based on the molecular and genetic alterations triggered by the infection.

Keywords: Mitochondria. Sepsis. Multiple organ failure. Metabolic adaption. Oxidative stress.

\section{Introducción}

Existe consenso en que la resucitación hemodinámica en el niño con choque séptico debe ser precoz y protocolizada'. Asimismo, la correcta y oportuna reanimación macrocirculatoria y microcirculatoria es de vital importancia para el pronóstico ${ }^{2-4}$.

El síndrome de disfunción multiorgánica (SDMO) se caracteriza por la falla simultánea de dos o más órganos o sistemas ${ }^{5}$. El desarrollo de SDMO es común en los pacientes ingresados en la unidad de cuidados intensivos (UCI). Dependiendo de la población estudiada, los criterios diagnósticos empleados y el fenotipo analizado en los pacientes con sepsis, la incidencia y la mortalidad son variables. El estudio SPROUT ${ }^{6}$ reportó un $25 \%$ de mortalidad hospitalaria por sepsis grave; de esta cohorte, el $58 \%$ presentó SDMO en el día de su reconocimiento, y el $40 \%$ falleció durante la hospitalización o desarrolló un nuevo o progresivo SDMO dentro de la semana siguiente. Villeneuve, et al. ${ }^{7}$ monitorizaron prospectivamente la ocurrencia diaria de SDMO en 842 pacientes de UCl. Según los criterios diagnósticos de Proulx y los de Goldstein, estos autores reportaron la existencia de SDMO en el $21.4 \%$ y el $37.3 \%$, respectivamente. Sin embargo, la proporción de pacientes con SDMO al momento de su admisión y que fallecieron dentro de los 90 días siguientes fue mayor en los diagnosticados con los criterios de Proulx. En fecha más reciente, un estudio nepalés encontró SDMO en el $51 \%$ de los pacientes admitidos en la $\mathrm{UCl}^{8}$.

En ocasiones, a pesar de obtener adecuadas metas de resucitación (hemodinámicas y metabólicas) y de un oportuno soporte vital, muchos pacientes con sepsis desarrollan SDMO y fallecen ${ }^{9-13}$. Esto sugiere la participación de otros mecanismos fisiopatológicos ${ }^{14,15}$, como la hipoxia citopática 0 , más precisamente, la disoxia citopática, que se origina por un desacoplamiento del sistema de producción energética celular (fosforilación oxidativa) ${ }^{16,17}$. Se ha propuesto, a modo de hipótesis, que la disfunción mitocondrial es una alteración relevante en el desarrollo de la falla orgánica inducida por sepsis, aunque no se encuentra totalmente caracterizada y su presencia no es necesariamente evidencia de causalidad ${ }^{14}$. No obstante, los trastornos metabólicos descritos sugieren que la disfunción mitocondrial podría ser un mecanismo involucrado ${ }^{18}$. Asimismo, la determinación de su papel (patogénico o adaptativo) -es decir, la supresión de actividades dependientes de energía en favor de otras esenciales para la sobrevida celular- es controversial ${ }^{19,20}$. Actualmente existe evidencia clínica de una mayor deficiencia bioenergética ${ }^{21,22}$ en los pacientes con sepsis que fallecen, lo que sugiere que la disfunción mitocondrial es un mecanismo fisiopatológico trascendente que, además, explicaría la presencia de fallas orgánicas en el paciente con choque séptico.

La terapia orientada a la disfunción mitocondrial («resucitación metabólica») parece una opción razonable, posible y promisoria para la prevención y el tratamiento del SDMO $23-25$.

El objetivo de la presente revisión es actualizar los conocimientos respecto a las alteraciones mitocondriales, el papel de su adaptación y, finalmente, realizar algunas breves consideraciones referentes a la resucitación mitocondrial en el paciente séptico con SDMO.

\section{Mitocondrias y respiración celular}

Las mitocondrias, presentes en todas las células eucariotas, son vestigios de un proceso ancestral endosimbiótico eubacteriano ( $\alpha$-proteobacterias) ocurrido hace más de un billón de años ${ }^{26,27}$. Su número, tamaño y forma pueden variar según el tipo de célula, tejido u órgano. Poseen dos tipos de ácido desoxirribonucleico (ADN): uno nuclear, que codifica la mayoría de las proteínas necesarias para los procesos metabólicos propios de la mitocondria, y otro independiente del genoma, denominado ADN mitocondrial $\left(\operatorname{ADN}_{\mathrm{mt}}\right)$, que contiene un total de 37 genes que codifican para el ácido ribonucleico (ARN) de transferencia (22 tARN), ARN ribosómicos (2 rARN) y ARN mensajeros (13 proteínas componentes del sistema de fosforilación oxidativa). Esta última característica es única y diferencia a la mitocondria de cualquier otro tipo de organelo. Además, el $\mathrm{ADN}_{\mathrm{mt}}$ contiene dinucleótidos $\mathrm{CpG}$ (islas $\mathrm{CpG}$ ) hipometilados que se asemejan al CpG del ADN 
bacteriano y son fundamentales en la activación de las vías de señalización y propagación de la inflamación ${ }^{28}$.

La estructura de la mitocondria está formada por dos membranas: una externa, lisa y que pertenece a la célula, y otra interna, que se encuentra plegada formando crestas mitocondriales, lo que le permite incrementar su superficie (estimada en $14,000 \mathrm{~m}^{2}$ de membrana interna en el ser humano) ${ }^{27}$. Esta capa interna pertenece al organelo y es impermeable (carece de poros). En ella se ubican las proteínas de la cadena transportadora de electrones (CTE), las proteínas transportadoras ubiquinona (coenzima $Q$ ) y citocromo $C$ (cit $C$ ), y los oxisomas o partículas $F$ (complejo enzimático adenosín trifosfato [ATP] sintasa). A su vez, la presencia de una doble membrana permite definir dos espacios, el espacio intermembrana y la matriz mitocondrial, rodeada por la membrana interna, que contiene, entre otras enzimas, las del ciclo de Krebs, el $\mathrm{ADN}_{\mathrm{mt}}$ y los ribosomas.

La función principal de las mitocondrias es la respiración celular, cuyo fin es producir energía. En la glucólisis, la rotura de una molécula de glucosa origina dos moléculas de ácido pirúvico, que se convierten en acetil-CoA por oxidación y descarboxilación (a través del sistema enzimático piruvato-deshidrogenasa). A su vez, esta se convierte en el principal precursor del ciclo de Krebs. La acetil-CoA dona electrones a la CTE, principalmente al complejo I.

La CTE consiste en un grupo de proteínas y moléculas organizadas en cuatro grandes complejos (I-IV), que se reducen y oxidan al transferirse entre ellas electrones procedentes de las formas reducidas de la nicotinamida adenina dinucleótido (NADH) y del flavín adenín dinucleótido $\left(\mathrm{FADH}_{2}\right)$, ambas moléculas originadas en las fases más tempranas de la respiración celular.

Como resultado, la energía liberada en la oxidación de estas moléculas, al ser mayor que la consumida en la reducción, se utiliza para bombear protones desde los complejos I, III y IV al espacio intermembrana, generando así un gradiente electroquímico (potencial de membrana de aproximadamente $-180 \mathrm{mV}$ ). El complejo IV, o citocromo $\mathrm{C}$ oxidasa, capta los electrones y los transfiere al oxígeno molecular, el cual es su aceptor final. Esta enzima es la encargada de la mayor parte del consumo de oxígeno del organismo (respiración).

La energía almacenada en este gradiente electroquímico, denominada fuerza protón-motriz, se debe a la diferencia de concentración de protones entre la matriz mitocondrial y el espacio intermembrana, denominada quimiosmosis, permitiendo la traslocación de protones desde el espacio intermembrana hacia la matriz a través de la proteína transmembrana ATP sintasa. La ATP sintasa cataliza la adición de un fosfato al adenosín difosfato (ADP) para finalmente sintetizar ATP. En conjunto, tanto el transporte de electrones como la quimiosmosis constituyen la fosforilación oxidativa (Figura 1).

En condiciones aeróbicas, la eficiente producción energética durante la fosforilación oxidativa representa un riesgo para la célula a consecuencia de la capacidad oxidante del oxígeno y de la formación de pequeñas cantidades de radicales libres (secundaria a la inevitable fuga de electrones) que dañan a las biomoléculas, ocasionando un efecto nocivo en la función y la sobrevida celular ${ }^{29}$. No obstante, en el paciente crítico con sepsis se ha descrito una importante reprogramación transcriptómica de genes mitocondriales ${ }^{30}$ y la activación de diversos mecanismos homeostáticos redox con el objetivo final de lograr una «autoprotección celular»31-33.

\section{Homeostasis mitocondrial en el sujeto sano}

Con excepción de los glóbulos rojos, todas las células del cuerpo poseen mitocondrias que desempeñan un papel clave en el metabolismo celular. Estas participan en más del $90 \%$ de la producción energética mediante la fosforilación oxidativa ${ }^{34}$, que es un proceso por el cual las enzimas de la CTE transforman el potencial eléctrico transmembrana $(\Delta \Psi \mathrm{\Psi m})$ en energía bioquímica. Junto con la fosforilación oxidativa basal, existe una capacidad respiratoria disponible que es la reserva de fosforilación mitocondrial destinada a responder al incremento de las demandas metabólicas (índice de reserva bioenergética).

La función mitocondrial varía en respuesta a factores intracelulares y extracelulares que regulan la homeostasis bioenergética celular. En condiciones de normalidad, el consumo de oxígeno a través de la CTE se encuentra estrechamente ligado a la producción de ATP (sustrato energético de los procesos metabólicos celulares) y regulado por la demanda metabólica (respiración acoplada).

Por otra parte, el oxígeno no empleado en la fosforilación oxidativa ( $1 \%$ del consumo de oxígeno mitocondrial) se destina a la producción de especies reactivas de oxígeno. Esta producción está estrictamente controlada por varias enzimas antioxidantes, como la 


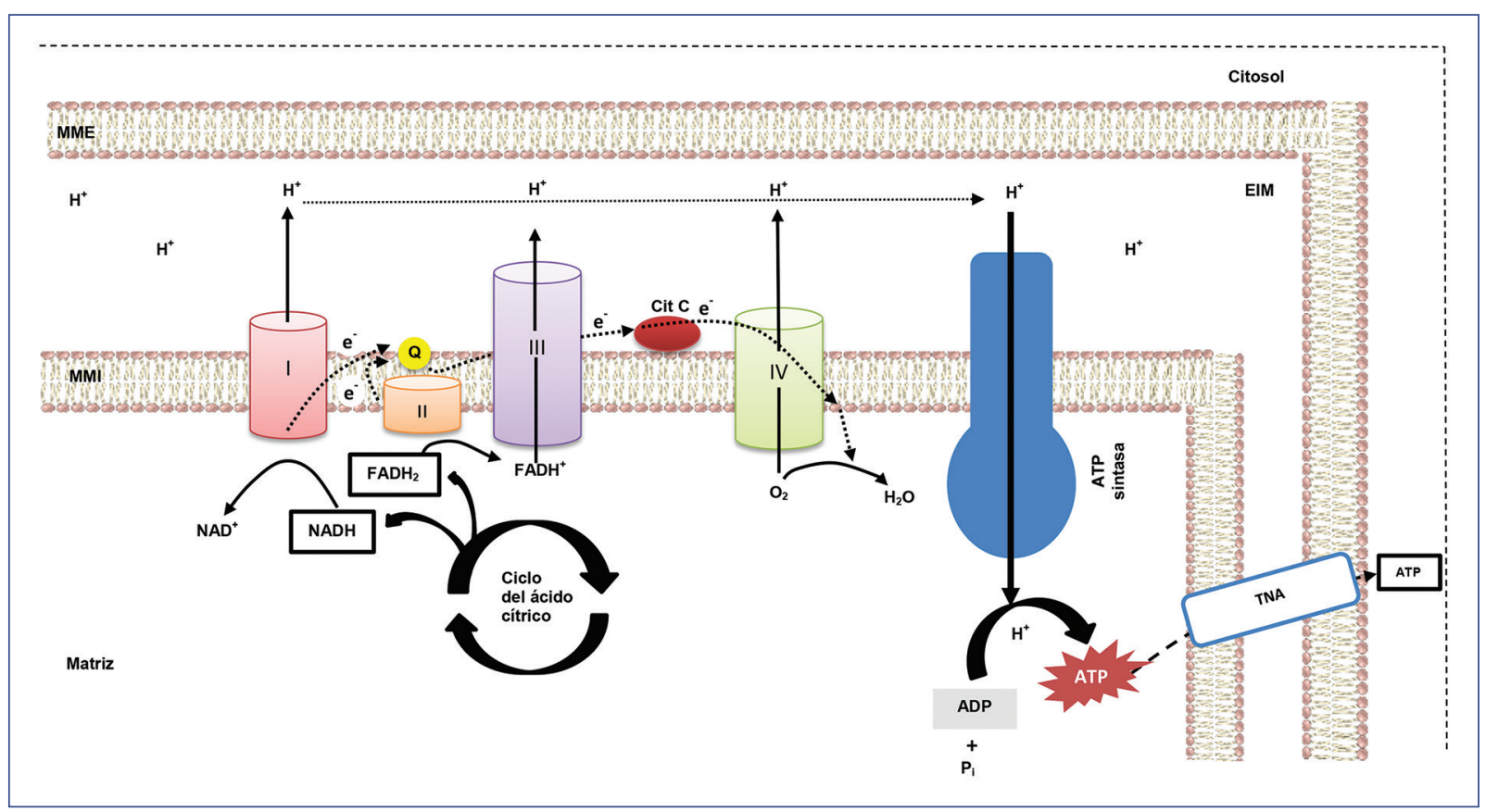

Figura 1. Representación esquemática de la fosforilación oxidativa y su interacción con el ciclo de Krebs. La cadena transportadora de electrones y la ATP sintasa se localizan insertadas en la membrana interna de la mitocondria. Los números romanos indican cada uno de los complejos de la cadena respiratoria. ADP: adenosín difosfato; ATP: adenosín trifosfato; Cit C: citocromo C; $\mathrm{FADH}^{+}$: flavín adenín dinucleótido forma oxidada; $\mathrm{FADH}_{2}$ : flavín adenín dinucleótido forma reducida; $\mathrm{H}^{+}$: protón; $\mathrm{H}_{2} \mathrm{O}$ : agua; MME: membrana mitocondrial externa; $\mathrm{MMI}$ : membrana mitocondrial interna; $\mathrm{NAD}^{+}$: nicotinamida adenina dinucleótido forma oxidada; $\mathrm{NADH}^{+}$: nicotinamida adenina dinucleótido forma reducida; $0_{2}$ : oxígeno; Pi: fosfato inorgánico; 0: coenzima 0; TNA: translocador de nucleótidos de adenina.

superóxido dismutasa manganeso o la glutatión oxidasa. Estas enzimas pueden desempeñar una función protectora o nociva en la señalización mitocondrial, dependiendo de la magnitud y la duración de su producción $^{35,36}$.

Finalmente, la homeostasis mitocondrial requiere un perfecto equilibrio entre la mitofagia y la biogénesis (incremento de la masa mitocondrial celular).

\section{Mortalidad por choque séptico en pediatría}

A pesar del conocimiento adquirido en las últimas décadas, la mortalidad hospitalaria de los niños con sepsis se mantiene elevada: del $19 \%$ en los países desarrollados y del $32 \%$ en aquellos en vías de desarrollo $^{37}$. Las razones por las cuales los niños fallecen son variables y, por lo tanto, los mecanismos por los que se puede esperar que una determinada intervención afecte la mortalidad requieren especial consideración. A modo de ejemplo, la mortalidad temprana debería ser menos frecuente debido a la precocidad en el reconocimiento y el inicio de la terapia de reanimación en el paciente séptico ${ }^{38}$. En contraparte, la mortalidad tardía (> 3 días) es atribuible, principalmente, a la persistencia del $\mathrm{SDMO}^{39}$. Así, las nuevas terapias dirigidas a la disfunción orgánica deberían reducir la mortalidad en aquellos niños que logran una estabilización inicial, pero que posteriormente no mejoran.

\section{Síndrome de distrés microcirculatorio y mitocondrial}

El paciente con sepsis que presenta una pobre respuesta terapéutica habitualmente tiene unas variables macrocirculatorias relativamente normales, pero con signos microcirculatorios asociados a un mal pronóstico, condición que se ha denominado síndrome de distrés microcirculatorio y mitocondrial (SDMM) ${ }^{40,41}$. Lo fundamental de esta propuesta es la presencia de hipoxia tisular que persiste tras la normalización de las variables de la macrocirculación ${ }^{42}$.

La hipoxia citopática se refiere a la alteración en la producción de ATP a pesar de la existencia de unos 
valores normales o supranormales de oxígeno tisu$\mid \mathrm{Iar}^{43,44}$. Esta condición puede deberse a factores tales como la disminución de la entrega de sustratos clave o la inhibición de etapas dentro del ciclo de Krebs, la alteración de las enzimas de la CTE o el desacoplamiento de la fosforilación oxidativa resultando en la producción de calor más que en la formación de ATP 16,45 .

Dos mecanismos se han propuesto para explicar el desarrollo del SDMM. El primero es una alteración de la microcirculación que se caracteriza por la disminución de la densidad de los capilares funcionales. De este modo, se incrementan tanto la distancia de difusión del oxígeno ${ }^{46}$ como la heterogeneidad capilar, generando un shunt microcirculatorio ${ }^{47}$, lo que implica una reprogramación metabólica: el cambio en la generación de ATP desde la fosforilación oxidativa a la glucólisis aerobia (efecto Warburg) y la inhibición de la CTE ${ }^{48}$; este segundo mecanismo es el que se ha planteado para el desarrollo del SDMM.

Dicha propuesta conceptual permitiría la identificación específica del compartimento donde ocurre la falla, y posibilitaría la instauración de estrategias terapéuticas adecuadas; las actuales están dirigidas casi en forma exclusiva a la corrección de la macrohemodinamia. Por consiguiente, el choque séptico, en parte, podría describirse fisiopatológicamente como un SDMM.

\section{Respuesta inmunitaria celular y respiración mitocondrial}

La respuesta protectora celular se desencadena por la activación de señales de «peligro» ante diferentes estímulos ${ }^{49}$. Existe evidencia de que los patrones moleculares asociados a patógenos microbianos (PAMP, pathogen-associated molecular patterns) y los patrones moleculares asociados al daño (DAMP, damage-associated molecular patterns), al ser identificados por los receptores de reconocimiento de patrones (PRR, pattern-recognition receptors), como Ios tipo Toll (TLR, Toll-like receptors), presentes en las células que participan en el sistema inmunitario innato, inician una respuesta sistémica por medio de las vías MyD88/TRADD/NF-KB y JAK1/STAT3 (Janus kinase 1-signal transducer and activator of transcription 3$)^{50}$. La activación de los TLR facilita la activación de la vía dependiente y de la vía independiente de MyD88. En la vía independiente (MyD88/TRADD/ NF-кB) se forma un complejo de señalización con TRADD (TNF-receptor asocciated via death domain) y otras proteínas acopladoras que conduce a la producción del interferón tipo I (IFN-I) y a la expresión de genes inducibles por IFN, y también involucra una fase tardía de activación de NF- $\mathrm{KB}^{51}$. De igual manera, diferentes citocinas utilizan la vía de señalización de JAK1/STAT3 para la transducción de señales desde la membrana celular al núcleo. Una vez que la citocina se une a su receptor, la JAK se activa, lo que estimula al factor de transcripción STAT, que a su vez induce a nivel nuclear los genes implicados en la producción de citocinas, las cuales son indispensables para la inmunidad innata y adaptativa ${ }^{52,53}$. Probablemente esta respuesta celular es modulada por la mitocondria ${ }^{54}$.

La activación de las células inmunitarias vía TLR aumenta la transcripción de citocinas proinflamatorias y antiinflamatorias, del factor de necrosis tumoral (TNF, tumor necrosis factor), de interleucinas (IL), de especies reactivas de oxígeno (como peróxido de hidrógeno o radical hidroxilo) y de especies reactivas de nitrógeno, incrementando el estrés oxidativo y nitrosativo. En este último ocurre un aumento de la producción de óxido nítrico que determina su reacción con el anión superóxido, originando peroxinitrito, especie altamente reactiva capaz de oxidar y nitrar componentes celulares y tisulares ${ }^{55}$. Este mecanismo, junto con el estrés oxidativo, ocasiona daño proteico y del ADN, como el bloqueo de la respiración mitocondrial, originando la disfunción mitocondrial inducida por sepsis (Figura 2) $^{42,56,57}$.

Por otra parte, los tratamientos empleados sistemáticamente en el paciente séptico, como antibióticos bactericidas ${ }^{58}$ y catecolaminas ${ }^{59}$, también pueden inhibir la respiración mitocondrial. Las catecolaminas, además de su acción hemodinámica, presentan propiedades que afectan a la inmunidad y al metabolismo del paciente grave ${ }^{60}$. En modelos animales clínicamente relevantes se ha observado una alteración de la respiración mitocondrial relacionada directamente con la dosis requerida de epinefrina ${ }^{61,62}$. A futuro, esta observación permitiría otra perspectiva sobre su utilización (descatecolaminización) ${ }^{59,63}$.

\section{Propagación de la inflamación y mitocondrias}

Las mitocondrias desempeñan un papel trascendental tanto en la propagación sistémica de la inflamación como en la disfunción de órganos distantes. El $A D N_{m t}$ es particularmente vulnerable al daño ocasionado por el estrés oxidativo y los mediadores proinflamatorios, 


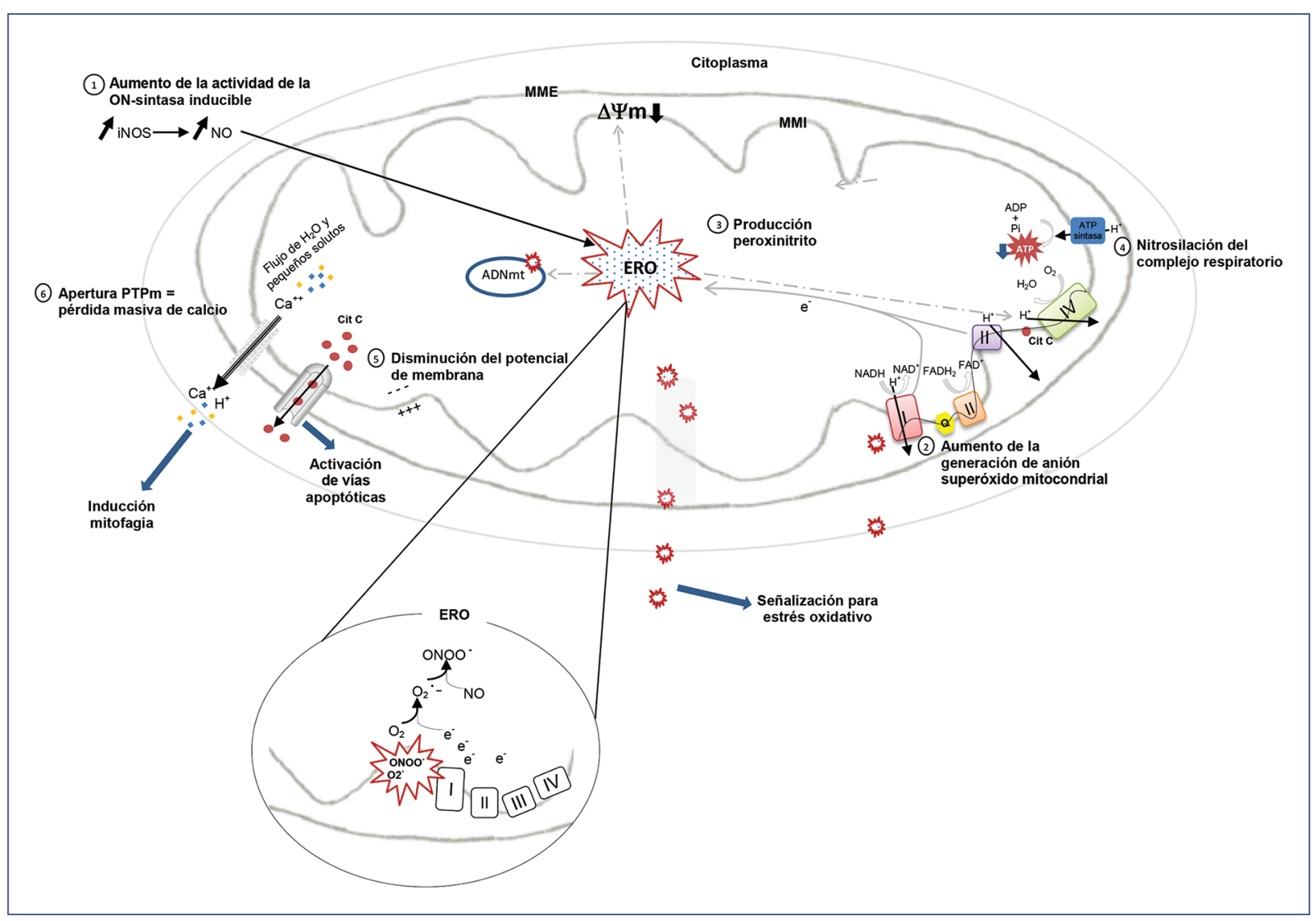

Figura 2. Sucesión de eventos causantes de disfunción mitocondrial en el paciente con sepsis. Los números romanos indican los complejos de la cadena respiratoria (I-IV). 1) Aumento de la actividad de la enzima óxido nítrico sintasa inducible. 2) Incremento de la producción de anión superóxido mitocondrial. 3) Producción de peroxinitrito. 4) Nitrosilación del complejo respiratorio. 5) Disminución del potencial de membrana. 6) Apertura de poro de transición mitocondrial. La disfunción de la cadena transportadora de electrones (CTE) da como resultado una producción intramitocondrial extrema de especies reactivas de oxígeno (ERO), lo que puede conducir a un daño oxidativo en la membrana, en la actividad de la CTE y el ADN mitocondrial. El incremento de permeabilidad de la membrana mitocondrial produce la liberación de citocromo C en el citosol; lo que conduce a apoptosis. El aumento de la permeabilidad de la membrana también hace que exista reflujo de $\mathrm{Ca}^{++}$hacia el citoplasma. Las ERO mitocondriales también pueden transportarse al citoplasma e inducir estrés oxidativo, seguido de la activación de vías de señalización de estrés oxidativo que modulan diversas funciones celulares. Finalmente, las ERO liberadas en el espacio extracelular dañarán a otras células y órganos (DAMP, damage-associated molecular patterns). $\mathrm{ADN}_{\mathrm{mt}}$ ácido desoxirribonucleico mitocondrial; ADP: adenosín difosfato; ATP: adenosín trifosfato; $\mathrm{Ca}^{++}$: calcio ionizado; $\mathrm{e}^{-}$: electrón; ERO: especies reactivas de oxígeno; $F A D^{+}$: flavín adenín dinucleótido forma oxidada; $\mathrm{FADH}_{2}$ : flavín adenín dinucleótido forma reducida; $\mathrm{H}^{+}$: protón; $\mathrm{H}_{2} \mathrm{O}$ : agua; iNOS: óxido nítrico sintasa inducible; MME: membrana mitocondrial externa; MMI: membrana mitocondrial interna; $\mathrm{NAD}^{+}$: nicotinamida adenina dinucleótido forma oxidada; $\mathrm{NADH}^{+}$: nicotinamida adenina dinucleótido forma reducida; NO: óxido nítrico; $\mathrm{O}_{2}$ : oxígeno; $\mathrm{O}_{2}^{-}$: anión superóxido; $\mathrm{ONOO}^{-}$: peroxinitrito; Pi: fosfato inorgánico; PTPm: poro de transición de permeabilidad mitocondrial; $\Delta \psi \mathrm{m}$ : potencial eléctrico transmembrana.

dada su proximidad con la CTE, la carencia de histonas protectoras, la limitada eficiencia de sus mecanismos de reparación y contener exclusivamente regiones codificadoras $^{64,65}$. De este modo, el $\mathrm{ADN}_{\mathrm{mt}}$ que se ha fragmentado es transportado a la matriz mitocondrial 0 al espacio extracelular (ADN ${ }_{\mathrm{mt}}$ extracelular), activando diversas vías inflamatorias debido a su similitud con el ADN bacteriano66-69.
Una vez que el $A_{D N}$ ha alcanzado el citosol, se promueve la formación del inflamasoma NLRP3 (nodlike receptor-P3 inflammasome), un complejo multimérico intracelular que desencadena la activación de caspasas inflamatorias, que a su vez generan la maduración proteolítica de la IL-1 $\beta$ y la IL-18, además de promover la expresión de IL-6 y TNF- $\alpha$, ambos procesos clave en la respuesta inmunitaria innata ${ }^{70}$. 


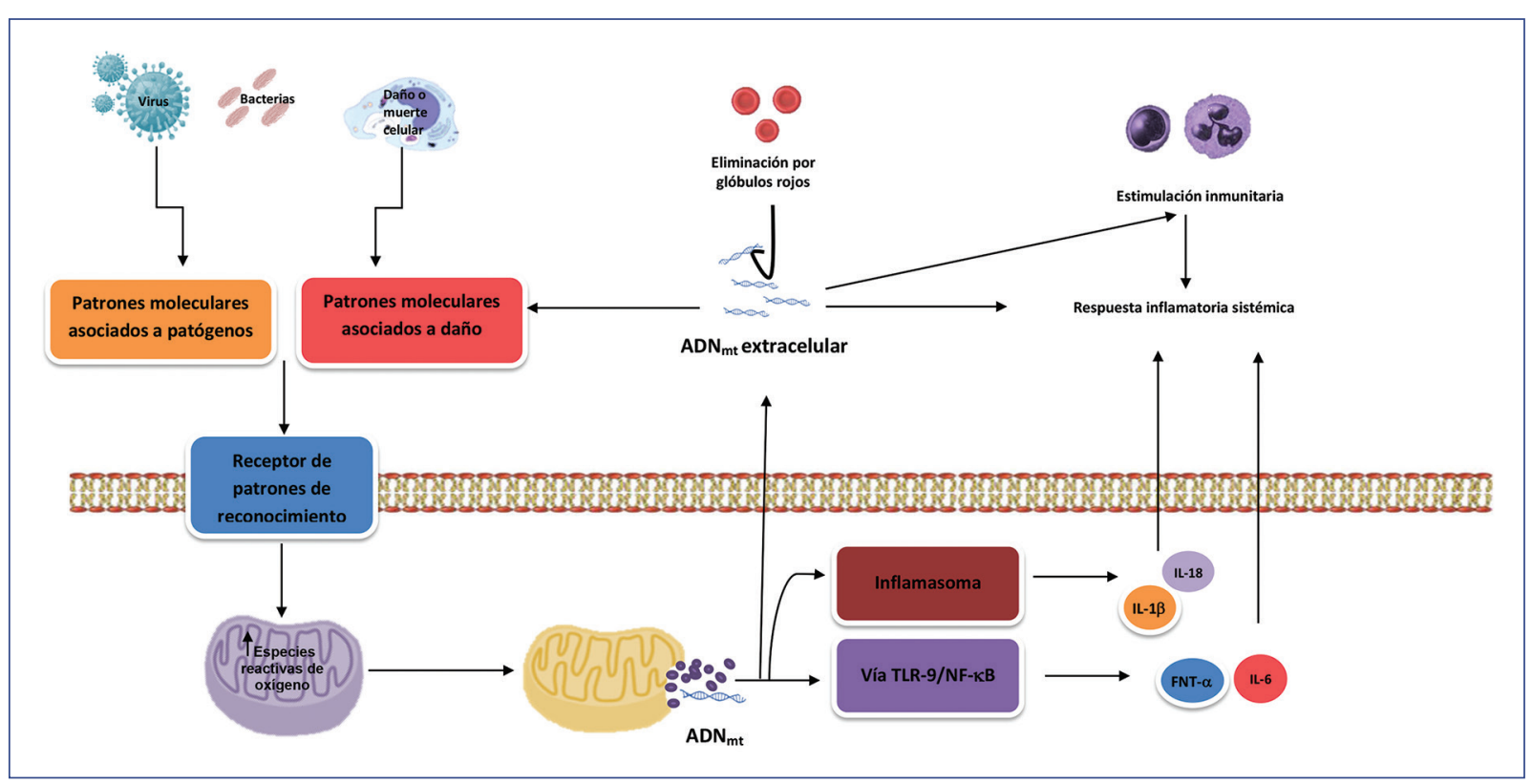

Figura 3. Representación de la producción y liberación del ácido desoxirribonucleico mitocondrial ( $\left.A D N_{m t}\right)$ extracelular. Los patrones moleculares asociados a patógenos (PAMP, pathogen-associated molecular patterns) y los patrones moleculares asociados al daño (DAMP, damage-associated molecular patterns), los cuales han sido liberados ante una infección o daño celular, respectivamente, ocasionan la estimulación de receptores de reconocimiento de patrones (PRR, pattern recognition receptors). Posteriormente se origina la producción de especies reactivas de oxígeno (ERO) mitocondrial, que dañan y fragmentan el $A_{D N}$ mt permitiendo su descompartimentalización y llegada al citosol. Este $\mathrm{ADN}_{\mathrm{mt}}$ actúa como un potente DAMP, estimulando el inflamasoma o la vía dependiente de los receptores Toll (TLR, Toll-like receptor), TLR-9/factor nuclear- $\kappa \beta$, ocasionando la producción de citocinas proinflamatorias. El ADN ${ }_{\text {mt }}$ puede alcanzar el medio extracelular, donde propaga la respuesta inflamatoria inicial al ser reconocido como DAMP por células inmunitarias y no inmunitarias. Se representa la eliminación del $A D N_{m t}$ circulante (cell-free $A D N_{m t}$ ) por los

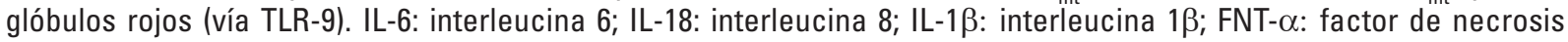
tumoral- $\alpha$. (Modificada de Harrington, et al. ${ }^{75}$.)

En la circulación, el $\operatorname{ADN}_{\mathrm{mt}}$ es reconocido como un potente $\mathrm{DAMP}^{71}$, desencadenando una respuesta infla-

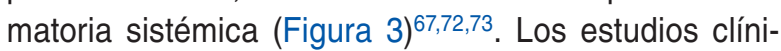
cos han demostrado la existencia de una asociación estadística entre sus niveles circulantes y la mortalidad, aunque la mayoría de los reportes son de series relativamente pequeñas y carecen de un protocolo estandarizado para su medición, aspectos que deben considerarse antes de establecer su real utilidad clínica como posible biomarcador ${ }^{74,75}$. En fecha más reciente se ha evaluado su valor pronóstico ${ }^{76}$ y también su correlación con el desarrollo de SDMO en niños con sepsis $^{77}$.

\section{Disfunción mitocondrial en el paciente con sepsis}

La relación entre la función mitocondrial y el SDMO aún no se ha esclarecido por completo; sin embargo, existe conocimiento de diversos papeles de las mitocondrias durante la sepsis (Tabla 1).

Las células del paciente con SDMO son incapaces de consumir el oxígeno disponible, ocasionando un daño en la CTE que genera un «apagón mitocondrial» $y$, como consecuencia, se produce deterioro de la bioenergética celular, exacerbación del estrés oxidativo y nitrosativo, incremento de la apoptosis y alteración de vías metabólicas esenciales ${ }^{78-81}$. Estos hallazgos han sido confirmados tanto en modelos animales ${ }^{21,82}$ como en humanos ${ }^{83}$, lo cual ratifica el papel de la disfunción mitocondrial en la patogenia del SDMO ${ }^{54}$. Brealey, et al. ${ }^{21}$ comunicaron menores cantidades de ATP en las biopsias muscular de pacientes fallecidos en comparación con los sobrevivientes. En la misma línea, la demostración de una mayor concentración tisular de oxígeno apoya el papel de la hipoxia citopática en la falla orgánica en el choque séptico ${ }^{16}$. 
Tabla 1. Funciones mitocondriales en el sujeto sano y durante el desarrollo de sepsis

Metabolismo y señalización celular

$\begin{array}{ll}\text { Fosforilación oxidativa } & \text { Fuente primaria de } \mathrm{VO}_{2} \text { y } \mathrm{VCO}_{2} \\ \text { Prioridades en el uso de } \\ \text { energía: transporte de } \mathrm{Na}^{+} \mathrm{y} \\ \text { Ca+2, síntesis proteica, } \\ \text { replicación de ADN y ARN }\end{array}$

Homeostasis $\mathrm{Ca}^{+2}$ intracelular Esencial para el normal Generación de especies funcionamiento celular reactivas de oxígeno y Riesgo potencial ante su nitrógeno exceso

\section{Daño mitocondrial y reparación}

\begin{tabular}{l|l}
$\begin{array}{l}\text { Apoptosis vía intrínseca: } \\
\text { citocromo C }\end{array}$ & $\begin{array}{l}\text { Requiere energía, efecto } \\
\text { antiinflamatorio }\end{array}$ \\
$\begin{array}{l}\text { Necrosis por rotura de } \\
\text { membrana }\end{array}$ & $\begin{array}{l}\text { Liberación de } \text { ADN }_{\mathrm{mt}} \text { (efecto } \\
\text { proinflamatorio, DAMP) } \\
\text { Ocasiona mecanismo de } \\
\text { mitofagia }\end{array}$ \\
\hline
\end{tabular}

Fusión, fisión y biogénesis Con el objetivo de mantener mitocondrial la salud mitocondrial

$A D N$ : ácido desoxirribonucleico; $\mathrm{ADN}_{\mathrm{mt}}$ : ácido desoxirribonucleico mitocondrial; ARN: ácido ribonucleico; DAMP: damage-associated molecular patterns (patrones moleculares asociados al daño); $\mathrm{VCO}_{2}$ : producción de dióxido de carbono; $\mathrm{VO}_{2}$ : consumo de oxígeno.

Finalmente, la restauración espontánea o farmacológica de la disfunción mitocondrial se asocia con recuperación del SDMO y con una mayor sobrevida. En concreto, en animales y en humanos ${ }^{22}$ se ha evidenciado que se logra la recuperación de la función orgánica y una mayor sobrevida ${ }^{54}$ cuando mejoran tanto la biogénesis mitocondrial como la mitofagia ${ }^{84-87}$. No obstante, esto podría tratarse solo de un epifenómeno, pues faltan estudios intervencionales que lo demuestren fehacientemente.

\section{Hibernación celular como causa de disfunción orgánica múltiple}

El suministro insuficiente de oxígeno ocasiona hipoxia tisular, mientras que la utilización alterada de este lleva a disoxia. Ambos mecanismos generan una reducción en la producción de ATP, provocando no solo disfunción celular en órganos específicos, sino también pérdida de la integridad celular, ya que mantener su estructura depende de la energía. Así, se podría suponer que, debido a las importantes alteraciones bioquímicas y metabólicas existentes en los pacientes que fallecen, la falla orgánica es consecuencia de una extensa muerte celular ${ }^{88}$. Sin embargo, los estudios post mortem han revelado una discordancia entre los hallazgos histológicos y la magnitud de la disfunción orgánica en los pacientes sépticos ${ }^{89,90}$.

Lo previamente mencionado, en concomitancia con un flujo sanguíneo preservado y la existencia de una tensión tisular de oxígeno adecuada ${ }^{91}$ asociada a un bajo consumo de este, han llevado a cuestionar el papel de la hipoxia tisular como principal mecanismo fisiopatológico en el paciente con SDMO.

Por ello, se necesita un paradigma que pueda explicar la existencia de la disfunción orgánica en ausencia de un daño estructural significativo y, aún más, ante un aporte adecuado de oxígeno ${ }^{92}$.

Una consecuencia notable de la activación de las vías de respuesta celular ante la presencia de señales de peligro es la supresión de las actividades dependientes de energía en favor de aquellas que son esenciales para la sobrevida celular, lo que se ha corroborado en cardiomiocitos (hibernación miocárdica) ${ }^{93,94}$, hepatocitos ${ }^{95}$ y neumocitos (conformidad hipóxica) ${ }^{96}$.

En esta misma línea, quizás el fenómeno de parálisis inmunitaria (vide infra), descrito en el paciente séptico ${ }^{97}$, refleje una hibernación leucocitaria en vista de que la respiración mitocondrial de las células mononucleares periféricas circulantes no puede responder ante un incremento de la demanda metabólica ${ }^{98-101}$. Asimismo, la escasa cantidad de células epiteliales tubulares necróticas observadas en el paciente con falla renal aguda es consistente con el concepto de hibernación epitelial renal ${ }^{102}$. Esta idea no es nueva, pues hace más de cuatro décadas ya se señaló que la falla renal aguda era, más bien, un «éxito» renal agudo, pues esta respuesta adaptativa permitía al riñón «ahorrar» en tareas altamente dependientes de energía (reabsorción tubular), configurando así un mecanismo de protección ${ }^{103}$.

El paradigma de la inflamación exacerbada no logra explicar por completo los eventos observados en los pacientes con sepsis. De hecho, durante este proceso también se liberan citocinas antiinflamatorias que buscan regular la respuesta inmunitaria, llegando a desarrollar, en ocasiones, un síndrome de respuesta antiinflamatoria compensatoria (CARS, compensatory anti-inflammatory response syndrome). La inmunoparálisis o CARS consiste en una hiperactividad de esta respuesta antiinflamatoria caracterizada por la alteración en la expresión del HLA-DR monocitario (mHLA-DR, monocytic human leukocyte antigen-DR), apoptosis linfocitaria y aumento de citocinas reguladoras $^{104}$, mecanismos que parecen influir en el desarrollo de infecciones secundarias y la muerte del paciente ${ }^{105}$. 


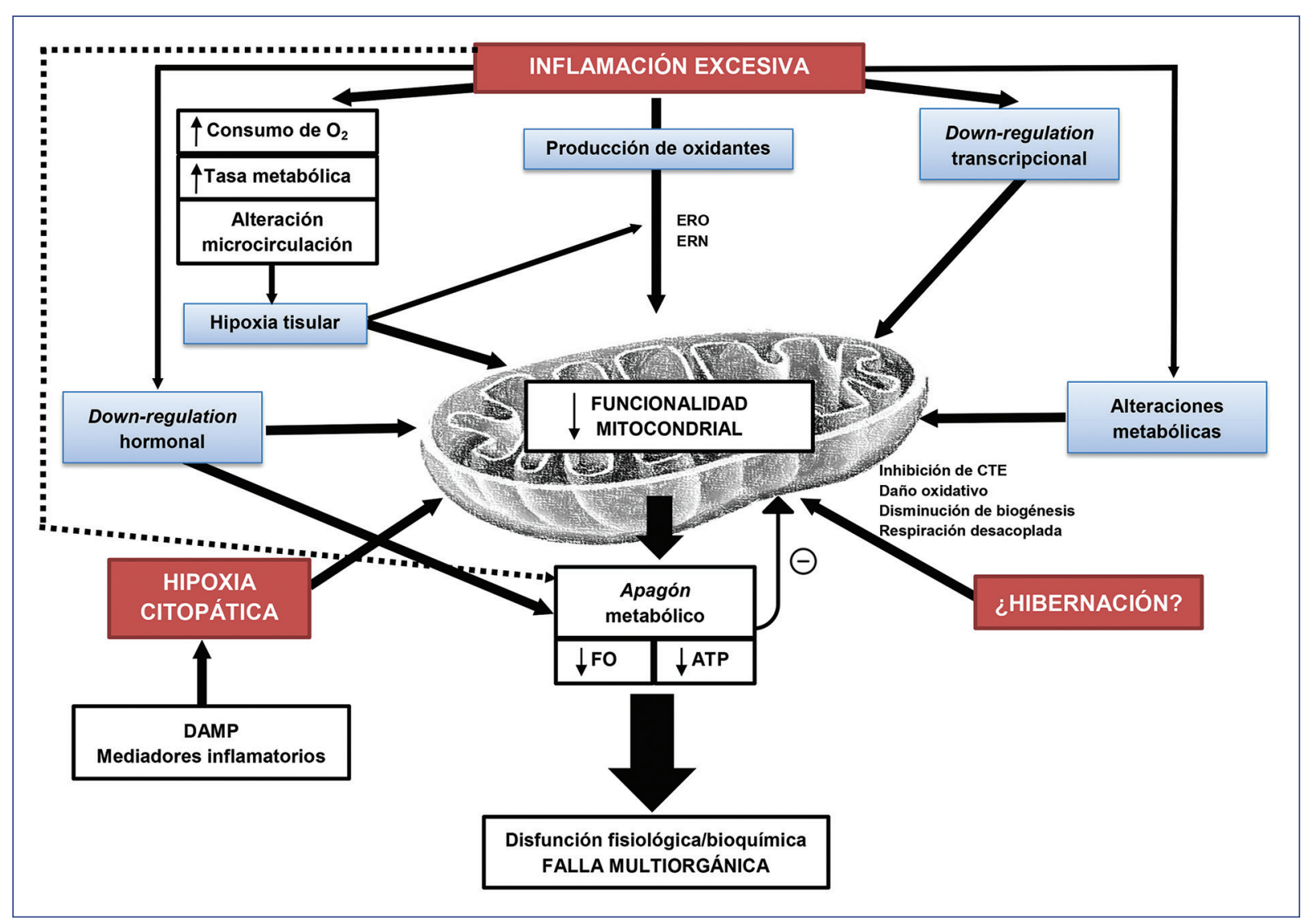

Figura 4. Mecanismos involucrados en la disfunción metabólica y apagón mitocondrial. ATP: adenosín trifosfato; CTE: cadena transportadora de electrones; ERO: especies reactivas de oxígeno; ERN: especies reactivas de nitrógeno; DAMP: damage-associated molecular patterns; FO: fosforilación oxidativa; $\mathrm{O}_{2}$ : oxígeno.

Lo previamente señalado sugeriría que el SDMO es un fenómeno más bien de carácter funcional que estructural, basado en una reducción primaria temporal del metabolismo celular ${ }^{79,106}$. Así, la falla multiorgánica puede verse como una respuesta adaptativa y protectora que ayudaría a prevenir la muerte celular (Figura 4).

Carcillo, et al. ${ }^{107}$ han señalado que el término "disfunción mitocondrial» sería una denominación errónea, ya que la regulación a la baja o la reducción temporal de la actividad metabólica observada en modelos experimentales probablemente representa una respuesta adaptativa (estado hipometabólico), hallazgo que con frecuencia se observa en los pacientes muy graves ${ }^{80,108}$.

Al parecer, esta idea estaría avalada por la observación de que la función orgánica usualmente se restaura (en días a semanas) en los pacientes sobrevivientes de SDMO, incluso en órganos con una pobre respuesta regenerativa, lo que indica que la disminución de la actividad mitocondrial es adaptativa e inicialmente reversible ${ }^{49,79,106}$.
El cambio desde el estado de apagón mitocondrial ${ }^{109}$ al de activación de la biogénesis ${ }^{22}$ se encuentra finamente regulado por diversos factores, los cuales dependerán de la gravedad de la sepsis, de factores genéticos ${ }^{110}$, de las características del individuo (edad, enfermedades asociadas) y de la terapia empleada ${ }^{111}$.

En suma, el SDMO refleja una respuesta funcional adaptativa, transitoria, protectora y potencialmente reversible, más que una lesión estructural, en el paciente con sepsis ${ }^{42}$.

\section{Monitorización de la función mitocondrial}

En la actualidad, la evaluación de la función mitocondrial se encuentra limitada al ámbito experimental y preclínico, principalmente mediante métodos ex vivo, lo que podría no ser representativo de una situación in vivo. Esto se debe a que la mitocondria es un organelo subcelular, y también a la comprensión inexacta y cabal de los procesos bioquímicos complejos que involucran a las reacciones redox, así como a la 
Tabla 2. Agentes farmacológicos propuestos para la prevención o la disminución de la disfunción mitocondrial séptica

\begin{tabular}{|c|c|c|c|}
\hline $\begin{array}{l}\text { Relacionados con la matriz mitocondrial y } \\
\text { la cadena transportadora de electrones }\end{array}$ & $\begin{array}{l}\text { Antioxidantes mitocondriales y } \\
\text { depuradores de radicales libres }\end{array}$ & $\begin{array}{l}\text { Estabilizadores de la } \\
\text { membrana mitocondrial }\end{array}$ & $\begin{array}{l}\text { Terapia hormonal } \\
\text { y otros }\end{array}$ \\
\hline Succinato & Mitoquinona ${ }^{c, d}$ & CsA/NIM 811 & Glucocorticoides \\
\hline Glutamina & Mito-Vit-E $E^{c, d}$ & Tetrametilpirazina & Insulina \\
\hline ATP-MgCl${ }^{2}$ & Péptidos SSc & Metformina & Melatonina \\
\hline L-carnitina & Mito-TEMPO ${ }^{c, d}$ & Imeglimina & Estrógenos \\
\hline Coenzima 0 (ubiquinona) & Tetrametilpiperidina (tempol) ${ }^{\mathrm{c}}$ & Ciclosporina & Leptina \\
\hline Citocromo C & Inhibidores NOS & & $\mathrm{CeO}_{2} \mathrm{NPS}$ \\
\hline Cafeína & N-acetilcisteína & & \\
\hline Ácido tióctico (ácido $\alpha$-lipoico) & Etilpiruvato & & \\
\hline rhTFAM ${ }^{a}$ & Inductor $\mathrm{HO}$ & & \\
\hline $\mathrm{H}_{2} \mathrm{~S}^{b}$ & Fenol (resveratrol) & & \\
\hline NOb & GSH & & \\
\hline \multicolumn{4}{|l|}{$\mathrm{CO}^{\mathrm{b}}$} \\
\hline $\begin{array}{l}\text { Promotor de la biogénesis. } \\
\text { Gasotransmisor. } \\
\text { Antioxidante sintético exógeno con diana en la mitocor } \\
\text { 'Catión lipófilo. } \\
\text { ATP-MgCl }: \text { adenosín trifosfato-cloruro de magnesio; } \mathrm{Ce} \\
\text { xigenasa; } \mathrm{H}_{2} \mathrm{~S} \text { : sulfuro de hidrógeno; NIM 811: } \mathrm{N} \text {-metil- } \\
\text { ranscripción mitocondrial recombinante humano. }\end{array}$ & $\begin{array}{l}\text { S: nanopartículas de óxido de cerio; CO } \\
\text { leucina; NO: óxido nítrico; NOS: óxido n }\end{array}$ & xido de carbono; CsA: ciclospo & $\begin{array}{l}\text { GSH: glutatión; HO: hemo } \\
\text { hTFAM: factor A de }\end{array}$ \\
\hline
\end{tabular}

incapacidad de realizar mediciones confiables en tiempo real en medios biológicos ${ }^{112}$.

Se dispone de técnicas in vivo, como la fluorometría para NADH, la espectroscopía por resonancia magnética y la espectroscopía cercana al infrarrojo (NIRS, near infrared spectroscopy) para medir el estado redox de la enzima citocromo $\mathrm{C}$ oxidasa ${ }^{113}$. Por otra parte, la tensión de oxígeno mitocondrial se puede evaluar en la epidermis mediante la fluorescencia de protoporfirina IX $\mathrm{X}^{114}$.

Aunque la magnitud de la disfunción mitocondrial inducida por la sepsis es variable en los diversos sistemas orgánicos comprometidos ${ }^{115}$, existe evidencia experimental en un modelo de choque hemorrágico de que la reducción de la respiración mitocondrial en células mononucleares periféricas se correlaciona con cambios similares en las mitocondrias del riñón y del corazón ${ }^{116}$. Por otro lado, en células mononucleares periféricas de niños sépticos se correlacionó el $\Delta \Psi m$ durante las primeras 48 horas con la magnitud del daño orgánico a la semana. Se evidenció un mayor $\Delta \Psi \mathrm{m}$ en aquellos pacientes con función orgánica normal al séptimo día en comparación con los que mostraron persistencia del SDMO posteriormente ${ }^{83}$. Weiss, et al. ${ }^{117}$ demostraron que la permanencia de una respiración mitocondrial disminuida en células mononucleares periféricas se asocia con una lenta recuperación de la función orgánica. Sin embargo, en esta misma línea, se requieren mayores estudios para la obtención de resultados concluyentes.

\section{Terapia farmacológica para la disfunción mitocondrial}

El listado de los agentes farmacológicos destinados a prevenir o tratar la disfunción mitocondrial en el paciente con sepsis es extenso (Figura 5). Estos pueden ser clasificados de una manera esquemática en las siguientes categorías: entrega de sustratos, cofactores y donantes de electrones favorecedores de la fosforilación oxidativa; aporte de antioxidantes exógenos y depuradores de radicales libres; estabilizadores de la membrana mitocondrial; y terapia hormonal (Tabla 2) $^{118,119}$

Además, es relevante conocer el momento adecuado de su aplicación o uso para una correcta evaluación 


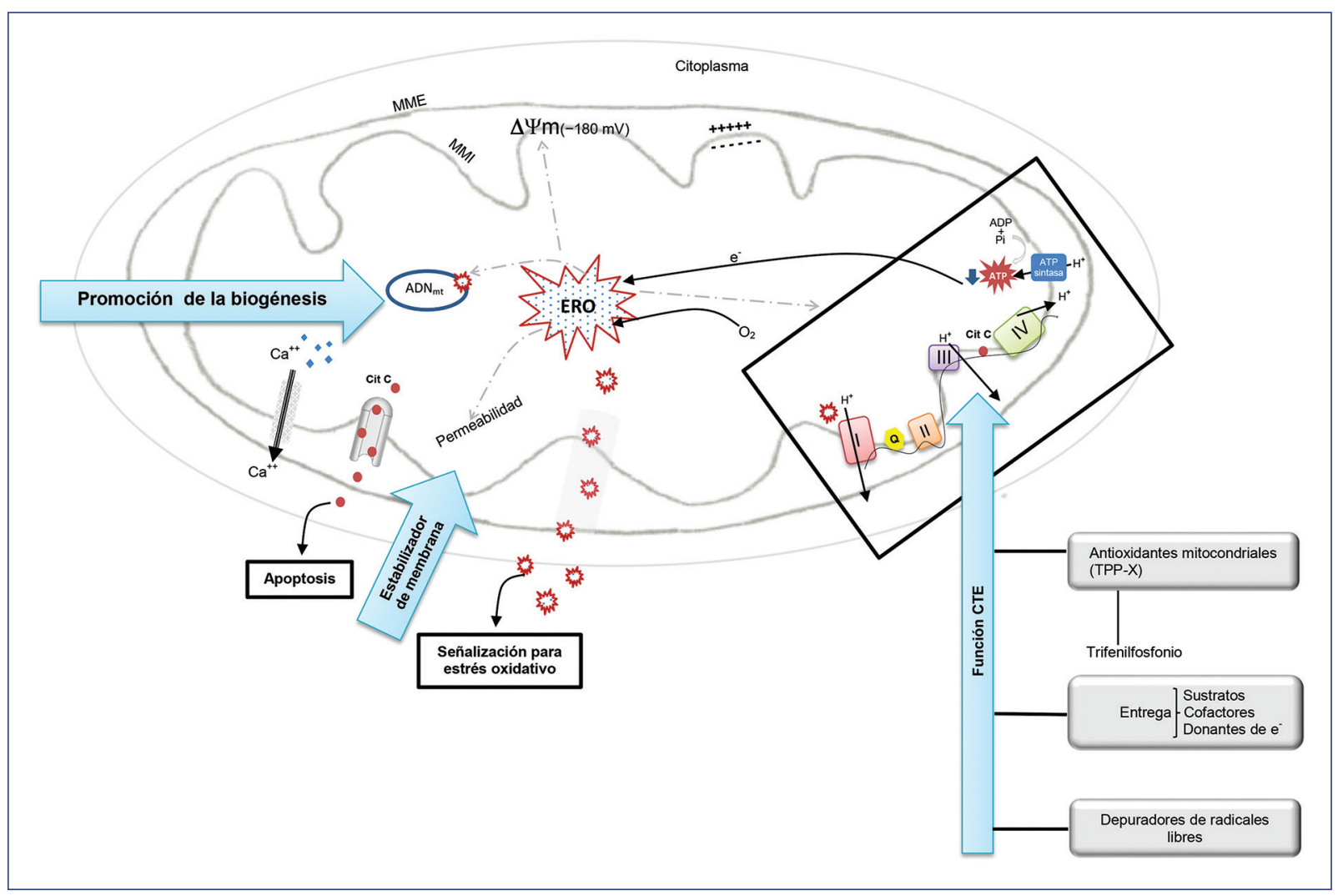

Figura 5. Estrategias terapéuticas con diana en la mitocondria. Los números romanos indican cada complejo de la cadena respiratoria. La terapia más promisoria son los antioxidantes conjugados con cationes (trifenilfosfonio, TPP+), los cuales se acumulan específicamente en las mitocondrias y mejoran la función de la cadena transportadora de electrones. La estabilización de la membrana inhibe que las especies reactivas de oxígeno provoquen más lesiones y protege a las mitocondrias de la inflamación y la rotura, reduciendo así la fuga de moléculas que causan apoptosis y alteración del calcio en el citoplasma. La promoción de la biogénesis mitocondrial reactiva las expresiones del ADN ${ }_{\text {mt' }}$ mejorando así la expresión de proteínas mitocondriales. ADN ; ácido desoxirribonucleico mitocondrial; ADP: adenosín difosfato; ATP: adenosín trifosfato; $\mathrm{Ca}^{++}$: calcio ionizado; Cit C: citocromo C; $\mathrm{e}^{-}$: electrón; ERO: especies reactivas de oxígeno; $\mathrm{H}^{+}$: protón; MME: membrana mitocondrial externa; $\mathrm{MMI}$ : membrana mitocondrial interna; $\mathrm{O}_{2}$ : oxígeno; Pi: fosfato inorgánico; 0: coenzima 0; $\Delta \psi \mathrm{m}$ : potencial eléctrico transmembrana. (Modificada de Zhang, et al. ${ }^{24}$.)

de su eficacia: a) prevención y restitución precoz de la disfunción mitocondrial; b) una vez establecida, prevención del colapso energético celular; c) en el periodo de biogénesis mitocondrial; $y$ d) en el periodo de reparación o sustitución de aquellas mitocondrias que se encuentran dañadas.

Experimentalmente, estas terapias han demostrado una disminución del estrés oxidativo y de las citocinas inflamatorias circulantes, junto con una restauración de la generación de ATP. Se han reportado los hallazgos de estudios preclínicos en modelos animales que han evaluado el efecto de diversos tipos de agentes sobre

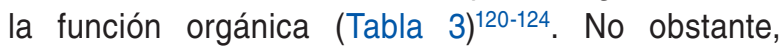
aún queda pendiente la valoración de su eficacia clínica ${ }^{125-127}$.

\section{A futuro}

Un desafío en el manejo de los pacientes con sepsis muy graves es reconocer el momento en que los esfuerzos terapéuticos, muchos de ellos orientados a la búsqueda de la normalidad fisiológica, pueden inducir modificaciones dañinas para la adecuada puesta en marcha del intento alostático adaptativo ${ }^{128,129}$.

La pronta identificación y el conocimiento del subgrupo de pacientes sépticos que se beneficiarían de una resucitación metabólica es esperable que se obtengan a través de la medicina de precisión mediante transcriptómica, metabolómica y farmacogenómica $^{31,130}$. Como la mayoría de las intervenciones terapéuticas en el paciente séptico, el momento en que 
Tabla 3. Trabajos experimentales en animales que evalúan el uso de diversas terapias farmacológicas antioxidantes mitocondriales y no antioxidantes

\begin{tabular}{|c|c|c|c|c|c|c|}
\hline Autor, año ${ }^{\text {ref }}$ & Sepsis & $\begin{array}{l}\text { Animal/ } \\
\text { modelo }\end{array}$ & Agente utilizado & Efectos orgánicos & $\begin{array}{l}\text { Efectos clínicos } \\
\text { observados }\end{array}$ & Mortalidad \\
\hline $\begin{array}{l}\text { Lowes, et al., } \\
2008^{120}\end{array}$ & Sí & $\begin{array}{l}\text { Ratones } \\
\text { LPS-PG }\end{array}$ & $\begin{array}{l}\text { Antioxidante } \\
\text { mitocondrial } \\
\text { (Mito0) }\end{array}$ & $\begin{array}{l}\text { Disminución de } \\
\text { marcadores bioquímicos } \\
\text { de disfunción hepática } \\
\text { Disminución de } \\
\text { marcadores bioquímicos } \\
\text { de disfunción renal }\end{array}$ & - & - \\
\hline $\begin{array}{l}\text { Patil, et al., } \\
2014^{121}\end{array}$ & Sí & $\begin{array}{l}\text { Ratones } \\
\text { LCP }\end{array}$ & $\begin{array}{l}\text { Antioxidante } \\
\text { mitocondrial } \\
\text { (Mito-TEMPO) }\end{array}$ & $\begin{array}{l}\text { Mejoría de la } \\
\text { microcirculación renal } \\
\text { Mejoría de la tasa de } \\
\text { filtración glomerular }\end{array}$ & - & $\begin{array}{l}\text { Incremento } \\
\text { a las } 96 \mathrm{~h} \text { en } \\
\text { la sobrevida } \\
\text { del } 40 \% \text { al } \\
80 \%\end{array}$ \\
\hline $\begin{array}{l}\text { Selvaraj, } \\
\text { et al., 2015 }\end{array}$ & Sí & $\begin{array}{l}\text { Ratones } \\
\text { LPS }\end{array}$ & $\begin{array}{l}\text { No antioxidante } \\
\left(\mathrm{CeO}_{2} \mathrm{NP}\right)\end{array}$ & $\begin{array}{l}\text { Disminución del daño } \\
\text { hepático }\end{array}$ & $\begin{array}{l}\text { Normalización de } \\
\text { temperatura, } \\
\text { frecuencia } \\
\text { respiratoria y presión } \\
\text { arterial }\end{array}$ & $\begin{array}{l}\text { Disminución } \\
\text { de la } \\
\text { mortalidad } \\
\text { del } 70 \% \text { al } \\
10 \%\end{array}$ \\
\hline $\begin{array}{l}\text { Xu, et al., } \\
2020^{123}\end{array}$ & Sí & $\begin{array}{l}\text { Ratones } \\
\text { LPS }\end{array}$ & $\begin{array}{l}\text { Mixto (estrógeno/ } \\
\text { Mito-TEMPO) }\end{array}$ & $\begin{array}{l}\text { Mitigación del daño } \\
\text { hepático con disminución } \\
\text { de AST y ALT } \\
\text { Menor grado de } \\
\text { infiltración hepática por } \\
\text { células inflamatorias }\end{array}$ & - & - \\
\hline $\begin{array}{l}\text { Xu, et al., } \\
2020^{124}\end{array}$ & Sí & $\begin{array}{l}\text { Ratones } \\
\text { LCP }\end{array}$ & $\begin{array}{l}\text { Nutrientes-antioxidantes } \\
\text { (ascorbato, taurina, } \\
\text { glutatión) }\end{array}$ & $\begin{array}{l}\text { Mitigación del daño } \\
\text { hepático con disminución } \\
\text { de ALT } \\
\text { Menor grado de } \\
\text { infiltración hepática por } \\
\text { células inflamatorias } \\
\text { Menor grado de necrosis } \\
\text { hepatocelular } \\
\text { Disminución de creatinina } \\
\text { plasmática }\end{array}$ & - & - \\
\hline
\end{tabular}

ALT: alanina aminotransferasa; AST: aspartato aminotransferasa; $\mathrm{Ce}_{2} \mathrm{NP}$ : nanopartículas de óxido de cerio; LCP: ligazón cecal y punción; LPS: lipopolisacárido; PG: peptidoglicano

estas se efectúen es de suma relevancia, ya que el organismo puede defenderse ante el incremento prematuro de su metabolismo.

La capacidad de identificar y seguir los cambios de la función mitocondrial (evaluación bioenergética) en el niño en riesgo de prolongación de la disfunción orgánica y que podría beneficiarse de una terapia mitocondrial será, entonces, un paso clave.

Finalmente, una atractiva e interesante área de desarrollo es la inducción farmacológica de un estado hipometabólico bajo demanda, ya sea global u orgánico, proceso denominado «animación suspendida»131,132.

El papel de la hipoxia citopática y la reanimación metabólica son campos de investigación activa. No obstante, los mecanismos precisos que están involucrados en la falla multiorgánica permanecen desconocidos.
Existe suficiente certeza para apoyar que la disfunción mitocondrial es clave en la fisiopatología del SDMO y que se caracteriza por una producción reducida de ATP con un incremento del estrés oxidativo. La evidencia orienta a la existencia de un apagón metabólico adaptativo originado por una reducción del metabolismo celular, en particular de la fosforilación oxidativa, priorizando la utilización de la energía para mantener la homeostasis del ATP.

El $A D N_{m t}$ liberado es reconocido como un importante desencadenante de la inflamación sistémica, que daña múltiples órganos y se asocia a mortalidad en los pacientes gravemente enfermos.

Existe controversia al analizar la disfunción mitocondrial en enfermedades graves, especialmente en modelos animales de sepsis, ya que no siempre se consideran las diferencias entre especies y entre 
órganos, o el momento en que se realiza su evaluación. Por esto, es necesario buscar modelos más representativos y que permitan su extrapolación al entorno clínico.

Los agentes farmacológicos para la prevención y el tratamiento de la disfunción mitocondrial, como aquellos para la inducción terapéutica de la biogénesis, son opciones atractivas y se constituyen en una promisoria línea de investigación para la resucitación metabólica. Sin embargo, ninguna se ha reflejado en la práctica clínica actual.

La monitorización de la oxigenación tisular y la función mitocondrial confiere un periodo ventana para determinar la suficiencia de la perfusión orgánica y del bienestar celular en el paciente séptico muy grave. Por lo tanto, queda pendiente definir quiénes son los pacientes candidatos a recibir terapia orientada a la mitocondria.

\section{Responsabilidades éticas}

Protección de personas y animales. Los autores declaran que para esta investigación no se han realizado experimentos en seres humanos ni en animales.

Confidencialidad de los datos. Los autores declaran que en este artículo no aparecen datos de pacientes.

Derecho a la privacidad y consentimiento informado. Los autores declaran que en este artículo no aparecen datos de pacientes.

\section{Conflicto de intereses}

Los autores declaran no tener ningún conflicto de intereses.

\section{Financiamiento}

Ninguno.

\section{Bibliografía}

1. Balamuth F, Weiss SL, Fitzgerald JC, Hayes K, Centkowski S, Chilutti M, et al. Protocolized treatment is associated with decreased organ dysfunction in pediatric severe sepsis. Pediatr Crit Care Med. 2016;17: 817-22.

2. Brierley J, Carcillo JA, Choong K, Cornell T, Decaen A, Deymann A, et al. Clinical practice parameters for hemodynamic support of pediatric and neonatal septic shock: 2007 update from the American College of Critical Care Medicine. Crit Care Med. 2009;37:666-88.

3. Weiss SL, Peters MJ, Alhazzani W, Agus MSD, Flori HR, Inwald DP, et al. Surviving Sepsis Campaign International Guidelines for the management of septic shock and sepsis-associated organ dysfunction in children. Pediatr Crit Care Med. 2020;21:e52-e106.

4. Legrand M, Ait-Oufella $\mathrm{H}$, Ince $\mathrm{C}$. Could resuscitation be based on microcirculation data? Yes. Intensive Care Med. 2018;44:944-6.
5. Goldstein B, Giroir B, Randolph A; International Consensus Conference on Pediatric Sepsis. International Pediatric Sepsis Consensus Conference: definitions for sepsis and organ dysfunction in pediatrics. Pediatr Crit Care Med. 2005:6:2-8.

6. Weiss SL, Fitzgerald JC, Pappachan J, Wheeler D, Jaramillo-Bustamante JC, Salloo A, et al.; Sepsis Prevalence, Outcomes, and Therapies (SPROUT) Study Investigators and Pediatric Acute Lung Injury and Sepsis Investigators (PALISI) Network. Global epidemiology of pediatric severe sepsis: the sepsis prevalence, outcomes, and therapies study. Am J Respir Crit Care Med. 2015;191:1147-57.

7. Villeneuve A, Joyal JS, Proulx F, Ducruet T, Poitras N, Lacroix J. Multiple organ dysfunction syndrome in critically ill children: clinical value of two lists of diagnostic criteria. Ann Intensive Care. 2016;6:40.

8. Giri A, Yadav SK, Sah V, Niroula N, Singh B. Multiple organ dysfunction syndrome-clinical profile, associations and outcome in critically ill children aged 1 month to 14 years admitted to PICU in Nobel Medical College Teaching Hospital in Biratnagar. Birat J Health Sci. 2019;4:629-33.

9. Watson RS, Crow SS, Hartman ME, Lacroix J, Odetola FO. Epidemiology and outcomes of pediatric multiple organ dysfunction syndrome. Pediatr Crit Care Med. 2017;18(3 Suppl 1):S4-S16.

10. Typpo KV, Petersen NJ, Hallman DM, Markovitz BP, Mariscalco MM. Day 1 multiple organ dysfunction syndrome is associated with poor functional outcome and mortality in the pediatric intensive care unit. Pediatr Crit Care Med. 2009;10:562-70.

11. Lin JC, Spinella PC, Fitzgerald JC, Tucci M, Bush JL, Nadkarni VM, et al.; Sepsis Prevalence, Outcomes, and Therapy Study Investigators. New or progressive multiple organ dysfunction syndrome in pediatric severe sepsis: a sepsis phenotype with higher morbidity and mortality. Pediatr Crit Care Med. 2017;18:8-16.

12. Leteurtre S, Duhamel A, Salleron J, Grandbastien B, Lacroix J, Leclerc F; Groupe Francophone de Réanimation et d'Urgences Pédiatriques (GFRUP). PELOD-2: an update of the PEdiatric Logistic Organ Dysfunction score. Crit Care Med. 2013;41:1761-73.

13. Weiss SL, Balamuth F, Hensley J, Fitzgerald JC, Bush J, Nadkarni VM, et al. The epidemiology of hospital death following pediatric severe sepsis: when, why, and how children with sepsis die. Pediatr Crit Care Med. 2017;18:823-30.

14. Singer $M$. The role of mitochondrial dysfunction in sepsis-induced multi-organ failure. Virulence. 2014;5:66-72.

15. Halbach JL, Wang AW, Hawisher D, Cauvi DM, Lizardo RE, Rosas J, et al. Why antibiotic treatment is not enough for sepsis resolution: an evaluation in an experimental animal model. Infect Immun. 2017;85:e00664.

16. Merz T, Denoix N, Huber-Lang M, Singer M, Radermacher P, McCook $\mathrm{O}$. Microcirculation vs. mitochondria - what to target? Front Med (Lausanne). 2020;7:416.

17. Lee I, Hüttemann M. Energy crisis: the role of oxidative phosphorylation in acute inflammation and sepsis. Biochim Biophys Acta. 2014;1842:1579-86.

18. Tappy $L$, Chioléro R. Substrate utilization in sepsis and multiple organ failure. Crit Care Med. 2007;35(9 Suppl):S531-4

19. Singer M, De Santis V, Vitale D, Jeffcoate W. Multiorgan failure is an adaptive, endocrine-mediated, metabolic response to overwhelming systemic inflammation. Lancet. 2004;364:545-8.

20. Boutilier RG. Mechanisms of cell survival in hypoxia and hypothermia. J Exp Biol. 2001;204(Pt 18):3171-81.

21. Brealey D, Brand M, Hargreaves I, Heales S, Land J, Smolenski R, et al. Association between mitochondrial dysfunction and severity and outcome of septic shock. Lancet. 2002;360:219-23.

22. Carré JE, Orban JC, Re L, Felsmann K, Iffert W, Bauer M, et al. Survival in critical illness is associated with early activation of mitochondrial biogenesis. Am J Respir Crit Care Med. 2010;182:745-51.

23. Leite HP, de Lima LF. Metabolic resuscitation in sepsis: a necessary step beyond the hemodynamic? J Thorac Dis. 2016;8:E552-7.

24. Zhang $\mathrm{H}$, Feng YW, Yao YM. Potential therapy strategy: targeting mitochondrial dysfunction in sepsis. Mil Med Res. 2018:5:41.

25. Reitsema VA, Star BS, de Jager VD, van Meurs M, Henning RH, Bouma HR. Metabolic resuscitation strategies to prevent organ dysfunction in sepsis. Antioxid Redox Signal. 2019;31:134-52.

26. Gray MW, Burger G, Lang BF. The origin and early evolution of mitochondria. Genome Biol. 2001;2:REVIEWS1018.

27. Rich P. Chemiosmotic coupling: the cost of living. Nature. 2003;421:583.

28. West AP, Shadel GS, Ghosh S. Mitochondria in innate immune responses. Nat Rev Immunol. 2011;11:389-402.

29. Eaton $S$. The biochemical basis of antioxidant therapy in critical illness. Proc Nutr Soc. 2006:65:242-9.

30. Matkovich SJ, AI Khiami B, Efimov IR, Evans S, Vader J, Jain A, et al. Widespread down-regulation of cardiac mitochondrial and sarcomeric genes in patients with sepsis. Crit Care Med. 2017:45:407-14

31. Nalos M, Parnell G, Robergs R, Booth D, McLean AS, Tang BM. Transcriptional reprogramming of metabolic pathways in critically ill patients. Intensive Care Med Exp. 2016;4:21.

32. Liu TF, Vachharajani V, Millet P, Bharadwaj MS, Molina AJ, McCall CE Sequential actions of SIRT1-RELB-SIRT3 coordinate nuclear-mitochondrial communication during immunometabolic adaptation to acute inflammation and sepsis. J Biol Chem. 2015;290:396-408. 
33. Chen X, Qian Y, Wu S. The Warburg effect: evolving interpretations of an established concept. Free Radic Biol Med. 2015;79:253-63.

34. Picard M, Taivassalo T, Gouspillou G, Hepple RT. Mitochondria: isolation, structure and function. J Physiol. 2011;589(Pt 18):4413-21.

35. Duchen MR. Mitochondria in health and disease: perspectives on a new mitochondrial biology. Mol Aspects Med. 2004;25:365-451.

36. Quoilin C, Mouithys-Mickalad A, Lécart S, Fontaine-Aupart MP, Hoebeke M. Evidence of oxidative stress and mitochondrial respiratory chain dysfunction in an in vitro model of sepsis-induced kidney injury. Biochim Biophys Acta. 2014;1837:1790-800.

37. García PCR, Tonial CT, Piva JP. Septic shock in pediatrics: the state-ofthe-art. J Pediatr (Rio J). 2020;96 (Suppl 1):87-98.

38. Cvetkovic M, Lutman D, Ramnarayan P, Pathan N, Inwald DP, Peters MJ. Timing of death in children referred for intensive care with severe sepsis: implications for interventional studies. Pediatr Crit Care Med. 2015;16:410-7.

39. Russell MJ, Kanthimathinathan HK. Is there an optimum duration of fluid bolus in pediatric septic shock? A critical appraisal of "Fluid bolus over 15-20 versus 5-10 minutes each in the first hour of resuscitation in children with septic shock: a randomized controlled trial" by Sankar et al. (Pediatr Crit Care Med 2017; 18:e435-e445). Pediatr Crit Care Med. 2018;19:369-71

40. Donoso FA, Arriagada SD, Cruces RP, Díaz RF. La microcirculación en el paciente crítico. Parte I: generalidades y fisiología en el paciente séptico. Rev Chil Pediatr. 2013;84:83-92.

41. Ince C. The microcirculation is the motor of sepsis. Crit Care. 2005;9 (Suppl 4):S13-9.

42. Navarrete ML, Cerdeño MC, Serra MC, Conejero R. Síndrome de distrés mitocondrial y de la microcirculación en el paciente crítico. Implicaciones terapéuticas. Med Intensiva. 2013;37:476-84.

43. Fink MP. Cytopathic hypoxia and sepsis: is mitochondrial dysfunction pathophysiologically important or just an epiphenomenon. Pediatr Crit Care Med. 2015:16:89-91.

44. Fink MP. Bench-to-bedside review: cytopathic hypoxia. Crit Care. 2002;6:491-9.

45. Leverve XM. Mitochondrial function and substrate availability. Crit Care Med. 2007;35(Suppl 9):S454-60.

46. De Backer D, Ospina-Tascon G, Salgado D, Favory R, Creteur J, Vincent $\mathrm{JL}$. Monitoring the microcirculation in the critically ill patient: current methods and future approaches. Intensive Care Med. 2010;36:1813-25.

47. Buwalda M, Ince C. Opening the microcirculation: can vasodilators be useful in sepsis? Intensive Care Med. 2002;28:1208-17.

48. Sygitowicz G. Sitkiewicz D. Molecular mechanisms of organ damage in sepsis: an overview. Braz J Infect Dis. 2020;24:552-60.

49. Schumacker PT, Gillespie MN, Nakahira K, Choi AM, Crouser ED, Piantadosi CA, et al. Mitochondria in lung biology and pathology: more than just a powerhouse. Am J Physiol Lung Cell Mol Physiol. 2014:306:L962-74.

50. Piantadosi CA, Suliman HB. Transcriptional control of mitochondrial biogenesis and its interface with inflammatory processes. Biochim Biophys Acta. 2012:1820:532-41.

51. O'Neill LA, Bowie AG. The family of five: TIR-domain-containing adaptors in Toll-like receptor signalling. Nat Rev Immunol. 2007;7:353-64.

52. O'Shea JJ, Plenge R. JAK and STAT signaling molecules in immunoregulation and immune-mediated disease. Immunity. 2012:36:542-50.

53. Schwartz DM, Bonelli M, Gadina M, O'Shea JJ. Type I/II cytokines, JAKs, and new strategies for treating autoimmune diseases. Nat Rev Rheumatol. 2016;12:25-36.

54. Arulkumaran N, Deutschman CS, Pinsky MR, Zuckerbraun B, Schumacker PT, Gomez H, et al. Mitochondrial function in sepsis. Shock. 2016;45:271-81.

55. Hurtado-Bredda FJ, Nin-Vaeza N, Rubbo-Amonini H. Estrés oxidativo y nitrosativo en la sepsis. Med Intensiva. 2005:29:159-65.

56. Garrabou G, Morén C, López S, Tobías E, Cardellach F, Miró O, et al. The effects of sepsis on mitochondria. J Infect Dis. 2012;205:392-400.

57. Akira S, Takeda K. Toll-like receptor signalling. Nat Rev Immunol. 2004;4:499-511

58. Kalghatgi S, Spina CS, Costello JC, Liesa M, Morones-Ramirez JR, Slomovic S, et al. Bactericidal antibiotics induce mitochondrial dysfunction and oxidative damage in mammalian cells. Sci Transl Med. 2013;5:192ra85

59. Rudiger A, Singer M. Decatecholaminisation during sepsis. Crit Care. 2016;20:309.

60. Hartmann C, Radermacher P, Wepler M, Nußbaum B. Non-hemodynamic effects of catecholamines. Shock. 2017;48:390-400.

61. Corrêa TD, Pereira AJ, Brandt S, Vuda M, Djafarzadeh S, Takala J, et al. Time course of blood lactate levels, inflammation, and mitochondrial function in experimental sepsis. Crit Care. 2017;21:105.

62. Merz T, Wepler M, Nußbaum B, Vogt J, Calzia E, Wang R, et al. Cystathionine- $\gamma$-lyase expression is associated with mitochondrial respiration during sepsis-induced acute kidney injury in swine with atherosclerosis. Intensive Care Med Exp. 2018;6:43.

63. Andreis DT, Singer M. Catecholamines for inflammatory shock: a JekyII-and-Hyde conundrum. Intensive Care Med. 2016;42:1387-97.

64. Van Remmen H, Richardson A. Oxidative damage to mitochondria and aging. Exp Gerontol. 2001;36:957-68
65. Yao X, Carlson D, Sun Y, Ma L, Wolf SE, Minei JP, et al. Mitochondrial ROS induces cardiac inflammation via a pathway through mtDNA damage in a pneumonia-related sepsis model. PLoS One. 2015;10:e139416.

66. Boyapati RK, Tamborska A, Dorward DA, Ho GT. Advances in the understanding of mitochondrial DNA as a pathogenic factor in inflammatory diseases. F1000Res. 2017;6:169.

67. Zhang Q, Raoof M, Chen Y, Sumi Y, Sursal T, Junger W, et al. Circulating mitochondrial DAMPs cause inflammatory responses to injury. Nature. 2010;464:104-7.

68. Ma KC, Schenck EJ, Pabon MA, Choi AMK. The role of danger signals in the pathogenesis and perpetuation of critical illness. Am J Respir Crit Care Med. 2018;197:300-9.

69. Harrington JS, Choi AMK, Nakahira K. Mitochondrial DNA in sepsis. Curr Opin Crit Care. 2017;23:284-90.

70. Kepp O, Galluzzi L, Kroemer G. Mitochondrial control of the NLRP3 inflammasome. Nat Immunol. 2011;12:199-200.

71. Timmermans K, Kox M, Scheffer GJ, Pickkers P. Danger in the intensive care unit: damps in critically ill patients. Shock. 2016:45:108-16.

72. Nakahira K, Haspel JA, Rathinam VA, Lee SJ, Dolinay T, Lam HC, et al. Autophagy proteins regulate innate immune responses by inhibiting the release of mitochondrial DNA mediated by the NALP3 inflammasome. Nat Immunol. 2011:12:222-30.

73. Aswani A, Manson J, Itagaki K, Chiazza F, Collino M, Wupeng WL, et al. Scavenging circulating mitochondrial DNA as a potential therapeutic option for multiple organ dysfunction in trauma hemorrhage. Front Immunol. 2018:9:891.

74. Nakahira K, Kyung SY, Rogers AJ, Gazourian L, Youn S, Massaro AF, et al. Circulating mitochondrial DNA in patients in the ICU as a marker of mortality: derivation and validation. PLoS Med. 2013;10:e1001577.

75. Harrington JS, Huh JW, Schenck EJ, Nakahira K, Siempos II, Choi AMK. Circulating mitochondrial DNA as predictor of mortality in critically ill patients: a systematic review of clinical studies. Chest. 2019;156:1120-36.

76. Yan HP, Li M, Lu XL, Zhu YM, Ou-Yang WX, Xiao ZH, et al. Use of plasma mitochondrial DNA levels for determining disease severity and prognosis in pediatric sepsis: a case control study. BMC Pediatr. 2018;18:267.

77. Di Caro V, Walko TD $3^{\text {rd }}$, Bola RA, Hong JD, Pang D, Hsue V, et al. Plasma mitochondrial DNA - a novel DAMP in pediatric sepsis. Shock. 2016;45:506-11.

78. Singer M. Mitochondrial function in sepsis: acute phase versus multiple organ failure. Crit Care Med. 2007;35(9 Suppl):S441-8.

79. Brealey D, Karyampudi S, Jacques TS, Novelli M, Stidwill R, Taylor V et al. Mitochondrial dysfunction in a long-term rodent model of sepsis and organ failure. Am J Physiol Regul Integr Comp Physiol. 2004;286:R491-7.

80. Cuzzocrea S, Mazzon E, Di Paola R, Esposito E, Macarthur H, Matuschak GM, et al. A role for nitric oxide-mediated peroxynitrite formation in a model of endotoxin-induced shock. J Pharmacol Exp Ther. 2006;319:73-81.

81. Kuznetsov AV, Kehrer I, Kozlov AV, Haller M, Redl H, Hermann M, et al. Mitochondrial ROS production under cellular stress: comparison of different detection methods. Anal Bioanal Chem. 2011;400:2383-90.

82. Crouser ED. Mitochondrial dysfunction in septic shock and multiple organ dysfunction syndrome. Mitochondrion. 2004;4:729-41.

83. Weiss SL, Selak MA, Tuluc F, Perales Villarroel J, Nadkarni VM, Deutschman CS, et al. Mitochondrial dysfunction in peripheral blood mononuclear cells in pediatric septic shock. Pediatr Crit Care Med. 2015;16:e4-e12.

84. Mannam P Shinn AS, Srivastava A, Neamu RF, Walker WE, Bohanon M, et al. MKK3 regulates mitochondrial biogenesis and mitophagy in sepsis-induced lung injury. Am J Physiol Lung Cell Mol Physiol. 2014;306:L604-19.

85. Haden DW, Suliman HB, Carraway MS, Welty-Wolf KE, Ali AS, Shitara H, et al. Mitochondrial biogenesis restores oxidative metabolism during Staphylococcus aureus sepsis. Am J Respir Crit Care Med. 2007;176:768-77.

86. Sunahara S, Watanabe E, Hatano M, Swanson PE, Oami T, Fujimura L, et al. Influence of autophagy on acute kidney injury in a murine cecal ligation and puncture sepsis model. Sci Rep. 2018;8:1050.

87. Cherry AD, Piantadosi CA. Regulation of mitochondrial biogenesis and its intersection with inflammatory responses. Antioxid Redox Signal. 2015;22:965-76

88. Rudiger A, Stotz M, Singer M. Cellular processes in sepsis. Swiss Med Wkly. 2008;138:629-34.

89. Hotchkiss RS, Karl IE. The pathophysiology and treatment of sepsis. N Engl J Med. 2003;348:138-50.

90. Langenberg C, Bagshaw SM, May CN, Bellomo R. The histopathology of septic acute kidney injury: a systematic review. Crit Care. 2008:12:R38.

91. Dyson A, Rudiger A, Singer M. Temporal changes in tissue cardiorespiratory function during faecal peritonitis. Intensive Care Med. 2011;37:1192-200.

92. Singer M. Critical illness and flat batteries. Crit Care. 2017;21(Suppl 3):309.

93. Ryan MJ, Perera $\mathrm{D}$. Identifying and managing hibernating myocardium: what's new and what remains unknown? Curr Heart Fail Rep. 2018:15:214-23.

94. Levy RJ, Piel DA, Acton PD, Zhou R, Ferrari VA, Karp JS, et al. Evidence of myocardial hibernation in the septic heart. Crit Care Med. 2005:33:2752-6. 
95. Kim PK, Chen J, Andrejko KM, Deutschman CS. Intraabdominal sepsis down-regulates transcription of sodium taurocholate cotransporter and multidrug resistance-associated protein in rats. Shock. 2000;14:176-81.

96. Vadász I, Dada LA, Briva A, Trejo HE, Welch LC, Chen J, et al. Amp-activated protein kinase regulates $\mathrm{co2}$-induced alveolar epitheliall dysfunction in rats and humans by promoting $\mathrm{Na}, \mathrm{K}-\mathrm{ATP}$ ase endocytosis. $\mathrm{J}$ Clin Invest. 2008;118:752-62.

97. Hall MW, Knatz NL, Vetterly C, Tomarello S, Wewers MD, Volk HD, et al. Immunoparalysis and nosocomial infection in children with multiple organ dysfunction syndrome. Intensive Care Med. 2011;37:525-32.

98. Hotchkiss RS, Monneret G, Payen D. Immunosuppression in sepsis: a novel understanding of the disorder and a new therapeutic approach. Lancet Infect Dis. 2013;13:260-8.

99. Maestraggi Q, Lebas B, Clere-Jehl R, Ludes PO, Chamaraux-Tran TN Schneider F, et al. Skeletal muscle and lymphocyte mitochondrial dysfunctions in septic shock trigger ICU-acquired weakness and sepsis-induced immunoparalysis. Biomed Res Int. 2017;2017:7897325.

100. Weiss SL, Zhang D, Bush J, Graham K, Starr J, Murray J, et al. Mitochondrial dysfunction is associated with an immune paralysis phenotype in pediatric sepsis. Shock. 2020;54:285-93.

101. Schäfer ST, Franken L, Adamzik M, Schumak B, Scherag A, Engler A et al. Mitochondrial DNA: an endogenous trigger for immune paralysis. Anesthesiology. 2016;124:923-33.

102. Gomez H, Ince C, De Backer D, Pickkers P, Payen D, Hotchkiss J, et al. A unified theory of sepsis-induced acute kidney injury: inflammation, microcirculatory dysfunction, bioenergetics, and the tubular cell adaptation to injury. Shock. 2014;41:3-11.

103. Thurau K, Boylan JW. Acute renal success. The unexpected logic of oliguria in acute renal failure. Am J Med. 1976;61:308-15.

104. Hall MW, Greathouse KC, Thakkar RK, Sribnick EA, Muszynski JA. Immunoparalysis in pediatric critical care. Pediatr Clin North Am. 2017:64:1089-102.

105. Hotchkiss RS, Opal S. Immunotherapy for sepsis - a new approach against an ancient foe. N Engl J Med. 2010;363:87-9.

106. Mongardon N, Dyson A, Singer M. Is MOF an outcome parameter or a transient, adaptive state in critical illness? Curr Opin Crit Care. 2009;15:431-6.

107. Carcillo JA, Podd B, Aneja R, Weiss SL, Hall MW, Cornell TT, et al. Pathophysiology of pediatric multiple organ dysfunction syndrome. $\mathrm{Pe}$ diatr Crit Care Med. 2017;18:S32-S45.

108. Levy RJ. Mitochondrial dysfunction, bioenergetic impairment, and metabolic down-regulation in sepsis. Shock. 2007;28:24-8.

109. Calvano SE, Xiao W, Richards DR, Felciano RM, Baker HV, Cho RJ, et al. A network-based analysis of systemic inflammation in humans. Nature. 2005;437:1032-7.

110. Baudouin SV, Saunders D, Tiangyou W, Elson JL, Poynter J, Pyle A, et al. Mitochondrial DNA and survival after sepsis: a prospective study. Lancet. 2005;366:2118-21.

111. Barnhill AE, Brewer MT, Carlson SA. Adverse effects of antimicrobials via predictable or idiosyncratic inhibition of host mitochondrial components. Antimicrob Agents Chemother. 2012;56:4046-51.

112. Typpo KV, Wong HR, Finley SD, Daniels RC, Seely AJ, Lacroix J. Monitoring severity of multiple organ dysfunction syndrome: new technologies. Pediatr Crit Care Med. 2017;18(3 Suppl 1):S24-S31.

113. Ekbal NJ, Dyson A, Black C, Singer M. Monitoring tissue perfusion, oxygenation, and metabolism in critically ill patients. Chest. 2013;143:1799-808.
114. Wefers Bettink MA, Harms FA, Dollee N, Specht PAC, Raat NJH, Schoonderwoerd GC, et al. Non-invasive versus ex vivo measurement of mitochondrial function in an endotoxemia model in rat: toward monitoring of mitochondrial therapy. Mitochondrion. 2020;50:149-57.

115. Karlsson M, Hara N, Morata S, Sjövall F, Kilbaugh T, Hansson MJ, et al. Diverse and tissue-specific mitochondrial respiratory response in a mouse model of sepsis-induced multiple organ failure. Shock. 2016;45:404-10.

116. Karamercan MA, Weiss SL, Villarroel JP, Guan Y, Werlin E, Figueredo R, et al. Can peripheral blood mononuclear cells be used as a proxy for mitochondrial dysfunction in vital organs during hemorrhagic shock and resuscitation? Shock. 2013;40:476-84.

117. Weiss SL, Zhang D, Bush J, Graham K, Starr J, Tuluc F, et al. Persistent mitochondrial dysfunction linked to prolonged organ dysfunction in pediatric sepsis. Crit Care Med. 2019;47:1433-41.

118. Murphy MP, Hartley RC. Mitochondria as a therapeutic target for common pathologies. Nat Rev Drug Discov. 2018;17:865-86.

119. Zheng G, Lyu J, Huang J, Xiang D, Xie M, Zeng Q. Experimental treatments for mitochondrial dysfunction in sepsis: a narrative review. J Res Med Sci. 2015;20:185-95.

120. Lowes DA, Thottakam BM, Webster NR, Murphy MP, Galley HF. The mitochondria-targeted antioxidant Mito $Q$ protects against organ damage in a lipopolysaccharide-peptidoglycan model of sepsis. Free Radic Biol Med. 2008;45:1559-65.

121. Patil NK, Parajuli N, MacMillan-Crow LA, Mayeux PR. Inactivation of renal mitochondrial respiratory complexes and manganese superoxide dismutase during sepsis: mitochondria-targeted antioxidant mitigates injury. Am J Physiol Renal Physiol. 2014;306:F734-43.

122. Selvaraj V, Nepal N, Rogers S, Manne ND, Arvapalli R, Rice KM, et al. Inhibition of MAP kinase/NF-kB mediated signaling and attenuation of lipopolysaccharide induced severe sepsis by cerium oxide nanoparticles. Biomaterials. 2015;59:160.

123. Xu Z, Mu S, Liao X, Fan R, Gao W, Sun Y, et al. Estrogen protects against liver damage in sepsis through inhibiting oxidative stress mediated activation of pyroptosis signaling pathway. PLoS One. 2020:15:e0239659.

124. Xu D, Liao S, Lv Y, Wang J, Kong L. NMR-based metabolomics approach reveals effects of antioxidant nutrients in sepsis-induced changes in rat liver injury. J Nutr Biochem. 2020;85:108440.

125. Manzanares W, Dhaliwal R, Jiang X, Murch L, Heyland DK. Antioxidant micronutrients in the critically ill: a systematic review and meta-analysis. Crit Care. 2012;16:R66.

126. von Dessauer B, Bongain J, Molina V Quilodrán J, Castillo R, Rodrigo R. Oxidative stress as a novel target in pediatric sepsis management. J Crit Care. 2011;26:103.e1-7.

127. Galley HF. Bench-to-bedside review: targeting antioxidants to mitochondria in sepsis. Crit Care. 2010;14:230.

128. Singer M, Glynne P. Treating critical illness: the importance of first doing no harm. PLoS Med. 2005;2:e167.

129. Stanzani G, Tidswell R, Singer M. Do critical care patients hibernate? Theoretical support for less is more. Intensive Care Med. 2020;46:495-7.

130. Farfán MJ, Torres JP. Diagnóstico en medicina en la era de las «omicas". Rev Chil Pediatr. 2018;89:163-5.

131. Hartmann C, Nussbaum B, Calzia E, Radermacher P, Wepler M. Gaseous mediators and mitochondrial function: the future of pharmacologically induced suspended animation? Front Physiol. 2017;8:691.

132. Hadj-Moussa H, Green SR, Storey KB. The living dead: mitochondria and metabolic arrest. IUBMB Life. 2018;70:1260-6. 